\title{
Üst ekstremitede tuzak nöropatileri - EMOT Hastanesi yaklaşımı
}

\section{Entrapment neuropathies of the upper extremity - EMOT hospital approach}

\author{
Yalçın Ademoğlu, Yusuf Gürbüz \\ EMOT Hastanesi, İzmir
}

Bu makalede, karpal tünel sendromu ve kübital tünel sendromunun tanı ve tedavi stratejilerine ilişkin, EMOT Hastanesi deneyimleri sunulmaktadır. Ayrıca, nüks karpal tünel sendromu ve kübital tünel sendromu ayırıcı tanısı ve tedavisinde önemli noktalar özetlenmiştir.

Anahtar sözcükler: karpal tünel sendromu; kübital tünel sendromu
In this article, the EMOT Hospital approach concerning the diagnosis and management strategies of carpal tunnel syndrome and cubital tunnel syndrome is presented. We also summarize the key diagnostic points and treatment guidelines for recalcitrant carpal tunnel syndrome and cubital tunnel syndrome.

Key words: carpal tunnel syndrome; cubital tunnel syndrome

\section{ÖĞRENIM HEDEFLERI}

- Karpal ve kübital tünel sendromunda, 25 yıllık birikimin oluşturduğu klinik yaklaşımı aktarmak.

- En değerli verilerin, öykü ve fizik muayeneden sağlandığını vurgulamak.

- Cerrahi gevşetmede, hasta memnuniyetini arttıran ayrıntıları sunmak.

- Nüks olgularda, etiyolojinin doğru tanımlanmasının önemini belirtmek.

\section{Giriş̧}

EMOT (El - Mikrocerrahi ve Ortopedi - Travmatoloji) Hastanesi arşiv kayıtlarında, 1991-2015 (Mayıs) yılları arasında, üst ekstremitede tuzak nöropatisi tanısı almış toplam 2946 hasta bulunmaktadır. Tablo 1'de görüldüğü gibi, bunların büyük çoğunluğunu karpal tünel sendromu (KTS) (\%85) ve kübital tünel sendromu (KuTS) (\%11) oluşturmaktadır. Toplam \%96'ık orana sahip KTS ve KuTS'lere ilişkin deneyimlerimizi aktarmanın daha anlamlı olacağı düşüncesiyle, bu yazıda sadece bunlardan söz edilecektir.

\section{KARPAL TÜNEL SENDROMU}

\section{Tanı}

Yakınmalar ve klinik bulgular, median sinirin etkilendiği basının şiddeti ve süresine göre değişiklik gösterdiği için farklı klinik tablolar oluşabilmektedir. ${ }^{[1]}$

\section{Öykü}

Median sinirin innerve ettiği parmakların hepsinde veya bazılarında (genellikle 3. parmakta), uyuşukluğun sadece geceleri ve/veya bazı aktiviteler sırasında (telefon konuşması, gazete okuma vs.) ortaya çıkması, erken evre KTS'de görülür. Karıncalanma ve uyuşukluk yakınmalarının gün içinde de devam ediyor olması ve güçsüzlük hissinin (elinden cisim düşürme) eklenmesi, median sinirde nöropraksi oluştuğunu (orta evre KTS) gösterir. Hastalığın ileri evresinde, median sinir alanında -bazı hastalarda tüm elde- sürekli duyu bozukluğu, el becerilerinin azalması ve bazen proksimale yayılan ağrı yakınmaları dikkat çekicidir.

\section{Muayene}

Her ne kadar, iyi bir anamnez ile hastalığın evresi yaklaşık olarak belirlenebilirse de, klinik muayenede

- İletişim adresi: Dr. Yalçın Ademoğlu, Emot Hastanesi. 1418 sk. No:14. Kahramanlar, İzmir Tel: 0232 - 4410121 e-posta: yalcinademoglu@yahoo.com

- Geliş tarihi: 13 Ekim 2015 Kabul tarihi: 13 Ekim 2015 
Tablo 1. EMOT hastanesinde üst ekstremitede tuzak nöropatisi tanısı almış hasta sayıları

\begin{tabular}{lcc}
\hline Tanı & Hasta sayısı & $\begin{array}{c}\text { Cerrahi tedavi } \\
\text { uygulanan hasta sayısı }\end{array}$ \\
\hline Median sinir & & 1327 \\
Karpal tünel sendromu & $2509(\% 85)$ & 5 \\
Anterior interosseöz sinir sendromu & $21(\% 0,7)$ & 3 \\
Pronator sendromu & $13(\% 0,5)$ & \\
Ulnar sinir & & 198 \\
Kubital tünel sendromu & $321(\% 11)$ & 5 \\
Ulnar tünel sendromu & $7(\% 0,2)$ & 5 \\
Radyal sinir & & 3 \\
Radyal tünel sendromu & $18(\% 0,6)$ & 1 \\
Posterior interosseöz sinir sendromu & $9(\% 0,3)$ & \\
Torasik çıkış sendromu & $48(\% 1,6)$ & 1542
\end{tabular}

Tinel bulgusu, Phalen testinin yanı sıra vibrasyon, SWE monofilaman ve 2NA (iki nokta ayrımı) testlerinin standart olarak yapılması gerekir. Otuz-altmış saniye içinde bulgu veren Phalen testinin duyarlılığı, KTS için oldukça yüksektir. El bileği fleksiyonu sınırlı olan hastalarda, Phalen testi yerine, median sinir kompresyon testi kullanılmalıdır. Tinel bulgusu, aksonal hasarda ortaya çıktığı için, erken evre KTS'de saptanamayabilir. Buna karşın, Phalen testi, kompresyon testi pozitifliği ve vibrasyon duyusunun bozulması, erken evre KTS'yi işaret eder. 2NA bozulması ( $>2-4 \mathrm{~mm}$ ) ile birlikte abduktor pollisis brevis (AbPB) kasında güçsüzlük veya atrofi, ileri evre KTS'nin tipik bulgularıdır.

KTS'de semptomlar ve muayene bulgularının duyarlılığı yüksek, özgüllüğü düşük olduğu için, mutlaka her iki üst ekstremitenin de sistemik muayenesi yapılmalıdır.

\section{Elektrodiyagnostik Testler}

Karpal tünel içindeki median sinir segmentine lokalize, sinir ileti hızının yavaşlaması, anahtar bulgudur. Deneyimlerimiz ve literatürde yer alan birçok çalışma, elektrodiyagnostik testlerin (EDT) KTS tanısına katkısının, öykü ve muayene bulgularından üstün olmadığı yönündedir. ${ }^{[2,3]}$ Buna rağmen, hastaların genellikle daha önce yapılmış EDT sonuçları ile başvurması ve yasal korunma gibi nedenlerle, EDT'ler standart protokolumuzda bulunmaktadır. Ayrıca, belirgin AbPB güçsüzlügü veya atrofisi varsa, servikal radikülopati veya motor nöron hastalığı ayırıcı tanısında EDT'ler çok yararlıdır.

\section{Ultrasonografi (US)}

Hastanemizde periferik sinir lezyonlarının tanısında sıkça US kullandığımız için, oldukça fazla deneyime sahibiz. ${ }^{[4]}$ US'yi, KTS düşünülen her hastada standart bir tanı aracı olarak kullanmıyoruz; ancak, klasik KTS doğal seyrinden farklı bir klinik tablo gösteren hastalarda (hipertrofik fleksör sinovya, tünel içi kitlesel lezyon, vb.), tanıya önemli katkılar sağlamaktadır. Cerrahi gevşetme sonrası KTS yakınmaları geçmeyen hastalarda (nüks KTS), transvers karpal bağın durumunu ve median sinir morfolojik yapısını (tünel içi anatomik seyri, ödem, perinöral fibrozis, parsiyel kesi, nöroma formasyonu vb.) değerlendirebilme ve belgeleyebilme olanağı sağladığı için, US'yi rutin olarak kullanıyoruz.

\section{Konservatif Tedavi}

Çalışma koşullarına bağlı yakın zamanda ortaya çıkmış ve erken evre KTS bulguları olan hastaları (arasıra olan, gece uyuşma/ağrı, gündüz yakınması yok, pozitif Phalen testi, pozitif vibrasyon testi), iş modifikasyonu ve el bileğini nötralde tespit eden gece ateli uygulaması ile takip ediyoruz. ${ }^{[5]}$ Üç-dört haftalık sürede, özellikle gece yakınmaları azalan hastalarda, atel kullanımına 2-3 ay kadar devam ediyoruz. Gözlemlerimiz, atellemenin gece yakınmalarını gidermede oldukça başarıı olduğu, ancak hastalığın ilerlemesini önlemede etkili olamadığı yönündedir.

\section{Cerrahi Tedavi}

\section{Anestezi}

Anestezi ekibimiz, KTS cerrahisinde bölgesel anestezi tekniklerini tercih etmektedir. Nörostimülatör ile US eşliğinde aksiller ve midhumeral blok uygulamasında, median sinir uzun etkili lokal anestezik (Bupivakain; 6-8 ml), diğer sinirler ise kısa etkili lokal anestezik ile (Lidokain; 4-8 $\mathrm{ml}$ ) bloke edilmektedir. 

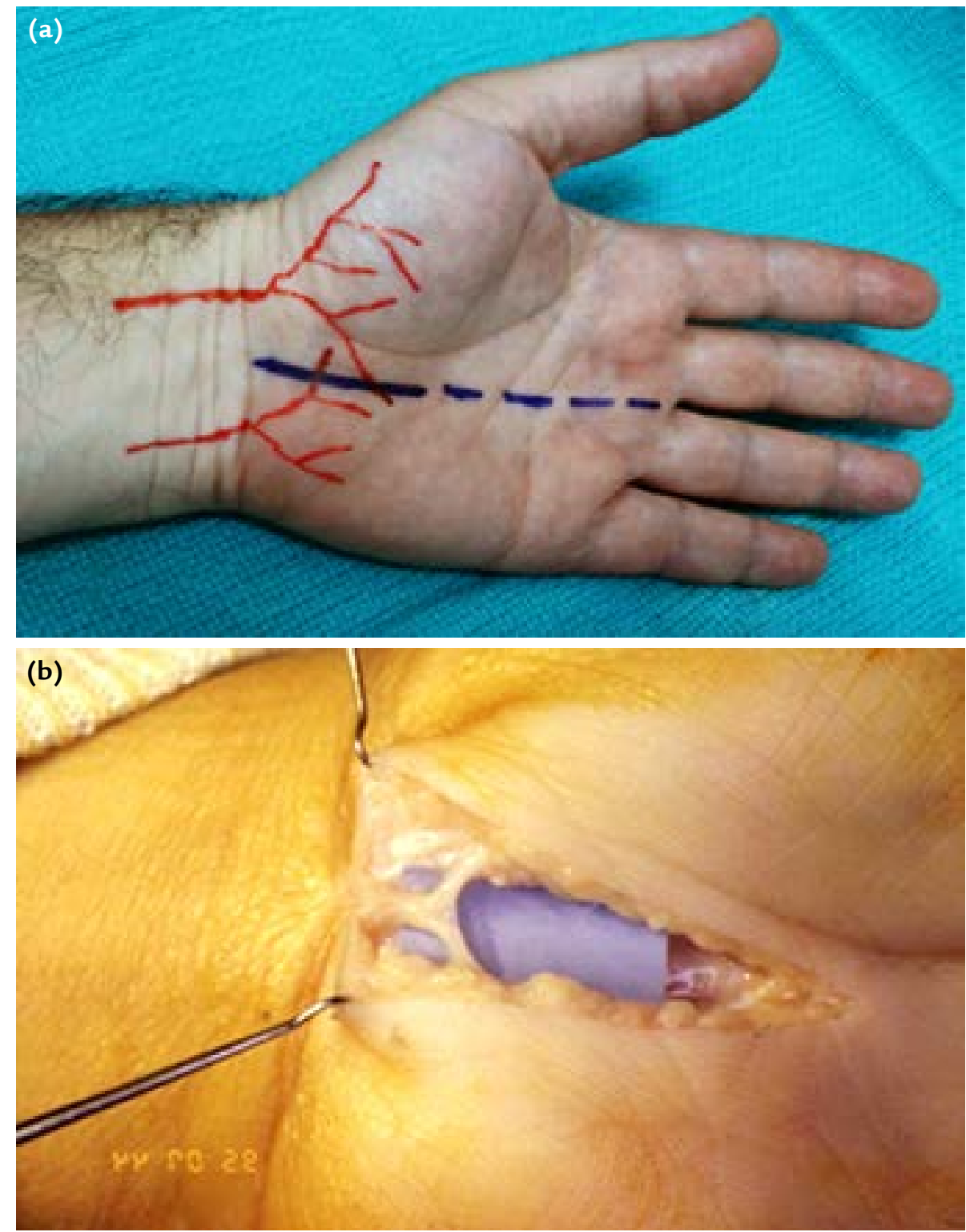

Şekil 1. a, b. Klasik kesi ile median ve ulnar sinirin palmar kutanöz dalları ilişkisi (a). Duyu sinirlerini koruyan açık karpal tünel gevşetmesi (b).

Bu yaklaşımımız ile, düşük doz lokal anestezik kullanımının yanı sıra, hastalar ameliyat sonrasında 8-24 saat süreyle ağrı duymamakta ve median sinir dışındaki sinirlere ait motor fonksiyonlarını erken dönemde kazanabilmektedirler.

\section{Cerrahi Yöntem}

Bazı dönemlerde, distal mini-kesi ile açık karpal tünel gevşetmesi ve endoskopik gevşetme (Chow tekniği) gibi yöntemler kullanılmış olmamıza rağmen, standart uygulamamız açık gevşetmedir.

\section{Duyu Sinirlerini Koruyan Açık Karpal Tünel Gevşetmesi}

Bu, uzun zamandır (1991'den beri) ve en sık tercih ettiğimiz yöntemdir. Pnömatik turnike kontrolü altında, geleneksel açık gevşetmedeki gibi, tenar krize paralel kesi ile girilir. Cilt altı yağ dokusu disseke edilerek, kesi bölgesini çaprazlayan, duyu sinirleri (median ve ulnar sinirin palmar kutanöz dalları) bulunur ve korunur (Şekil 1). Gevşetme sırasında, transvers karpal bağın, karpal tünelin ulnar kenarından açılmasına ve olası motor dal varyasyonlarına özen gösterilir. Tünel içindeki median sinir segmentinde kum saati deformitesi 
varsa, internal nöroliz yapmaksızın, sadece epinörotomi yapılır.

Bir yıldan daha uzun zamandır AbPB kas atrofisi olan ileri evre KTS'de, hasta kabul ederse, başparmağa oppozisyon kazandırmak için, palmaris longus (PL) tendonu ile abduktorplasti (Camitz transferi) uyguluyoruz. Bu hastalarda, rehabilitasyon gereksinimi nedeniyle, tedavi üç aya kadar uzayabilmektedir.

Ameliyat sonrası atel kullanmıyoruz. Bol pamuklu, kompresif sargılama ile el bileği nötral pozisyonda tespit edilir. Ertesi gün omuz, dirsek ve parmak eklemlerinde aktif harekete başlanır. Bir hafta sonra hasta kontrole çağrılır, kesi bölgesi küçük bir pansuman ile kapatılıp, ödem oluşmaması için tubigrip verilir ve ağrı sınırlarında aktif el bileği hareketlerine başlanır. Elin hafif günlük aktivitelerde kullanımına, üçüncü haftadan sonra izin verilir. ilk kontrol muayenesinde, el ve parmaklarda belirgin ödem ve eklem sertliği gözlenirse, hasta fizyoterapi programına alınır.

\section{Komplikasyonlar}

Bir hastada motor dal yaralanması $(1 / 1327)$ ve üç hastada kompleks bölgesel ağrı sendromu (3/1327), karşılaştığımız ciddi komplikasyonlardı. Uyguladığımız duyu sinirlerini koruyan cerrahi teknik nedeniyle, kesi yeri duyarlılığı ve yastık ağrısı gibi sorunları nadiren görmekteyiz.

\section{Nüks KTS'ye Yaklaşım}

Tedavisi en zor hasta grubudur. Farklı semptomlar ve muayene bulguları ile değişik klinik tablolar oluşabilmektedir. ${ }^{[6]}$ En belirgin yakınma ağrıdır. Zamanla psikojenik komponentin de eklenmesi, mevcut durumu daha karmaşık hale getirir. Cerrahi gevşetme sonrası devam eden ağıının doğru tanımlanması, en kritik noktalardan biridir.

\section{Ameliyat Sonrası Ağrının Hiç Geçmemesi}

Öncelikle yanlış tanı olasılığı düşünülmeli, proksimal patolojiler (servikal radikülopati, double crush sendromu, pronator sendrom, sinir tm. vs.) ekarte edilmelidir. KTS tanısı doğruysa, yetersiz gevşetmeye odaklanmalıdır.

\section{Ameliyattan Sonra Ağrının Geçip, Bir Süre Sonra Tekrar Başlaması}

ilk 6-8 ay içinde, ameliyat öncesi semptomlara benzer yakınmalarla ortaya çıkar. Sebep, genellikle, perinöral fibrozis ve tünel içinde skar dokusu oluşumudur.

\section{Yeni Bir Ağrının Başlaması}

En sık, yastık ağrısı olarak karşımıza çıkar. Median veya ulnar sinirin palmar duyu dallarının yaralanması ile oluşan nöromalar ve kompleks bölgesel ağrı sendromunun gelişmesi, olası nedenlerdendir.

Nüks KTS'de sıklıkla yapılan hata, sadece EDT sonuçlarına göre cerrahi tedaviye karar verilmesidir. Öncelikle, hastanın sistemik değerlendirmesi ve ekstremitenin ayrıntılı muayenesi, temel yaklaşım olmalıdır. Transvers karpal bağ, median sinir ve fleksör tendonların durumunu belirlemede US önemli katkılar sağlamaktadır (Şekil 2).

\section{KÜBITAL TÜNEL SENDROMU}

Standart semptomları ve fizik muayene bulguları 10 . bölümde geniş olarak anlatılan KuTS tanı ve tedavisinde yanlış ya da yetersiz yaklaşımlara, KTS'den daha fazla karşılaşmaktayız. Bu durum, genellikle, KuTS patolojisindeki varyasyonlar ve deneyim eksikliğinden kaynaklanmaktadır.

\section{Tanı}

Dirsekte fleksiyon-ekstansiyon hareketi gerektiren aktiviteler sırasında semptomların ortaya çıkıp, dinlenmekle geçmesi, erken evre KuTS'nin ipuçlarıdır. Sistemik hastalık sorgulaması mutlaka yapılmalıdır. Klasik yakınmalara eşlik eden, tüm kola yayılan ağrı, kısa zamanda gelişen atrofi, hızlı zayıflama gibi, atipik bulgular dikkate alınmalıdır.

Fizik muayeneye boyundan başlayıp, hipotenar bölgeye kadar tüm ulnar sinir kontrol edilmelidir. Özellikle, ulnar sinir trasesi boyunca, Tinel bulgusu aranmalıdır.

\section{Örnek Olgu}

Mc Gowan Evre III KuTS tanısı ile, hastaya ulnar sinirin anterior transpozisyon girişimi yapıldıktan sonra, hiçbir iyileşme olmamış. Farklı merkezlerde yapılan dirsek ve boyun manyetik rezonans (MR) görüntüde herhangi bir proksimal patoloji saptanamamış. Dirseğe lokalize elektrodiyagnostik incelemelerde KuTS rapor edilmiş. ilk ameliyattan üç ay sonra ikinci kez ameliyat önerilmiş ve ulnar sinirin dirsek bölgesinde eksplorasyonu planlanmış. Bu hastada, sadece inspeksiyon ve Tinel bulgusu ile infraklaviküler-aksiller bölgede (boyun ve dirsek MR görüntüleme alanları dışında) kitlesel lezyon saptadık (Şekil 3).

Dirsek fleksiyon testi pozitifliği, KuTS için en iyi tanısal bulgudur. Test sırasında (dirsek $>90^{\circ}$ fleksiyon, önkol supinasyon, el bileği ekstansiyon) omuzu abduksiyona getirmek, bu testin tanısal kapasitesini arttırır. Duyu testleri (vibrasyon, SWE monofilaman, 2NA), sadece 5. parmak pulpasını değil, el dorso-ulnarını da (n. ulnaris dorsal duyu dalı alanı) kapsamalıdır. Burada duyunun normal bulunması durumunda, Guyon kanaIı gözden geçirilmelidir. 

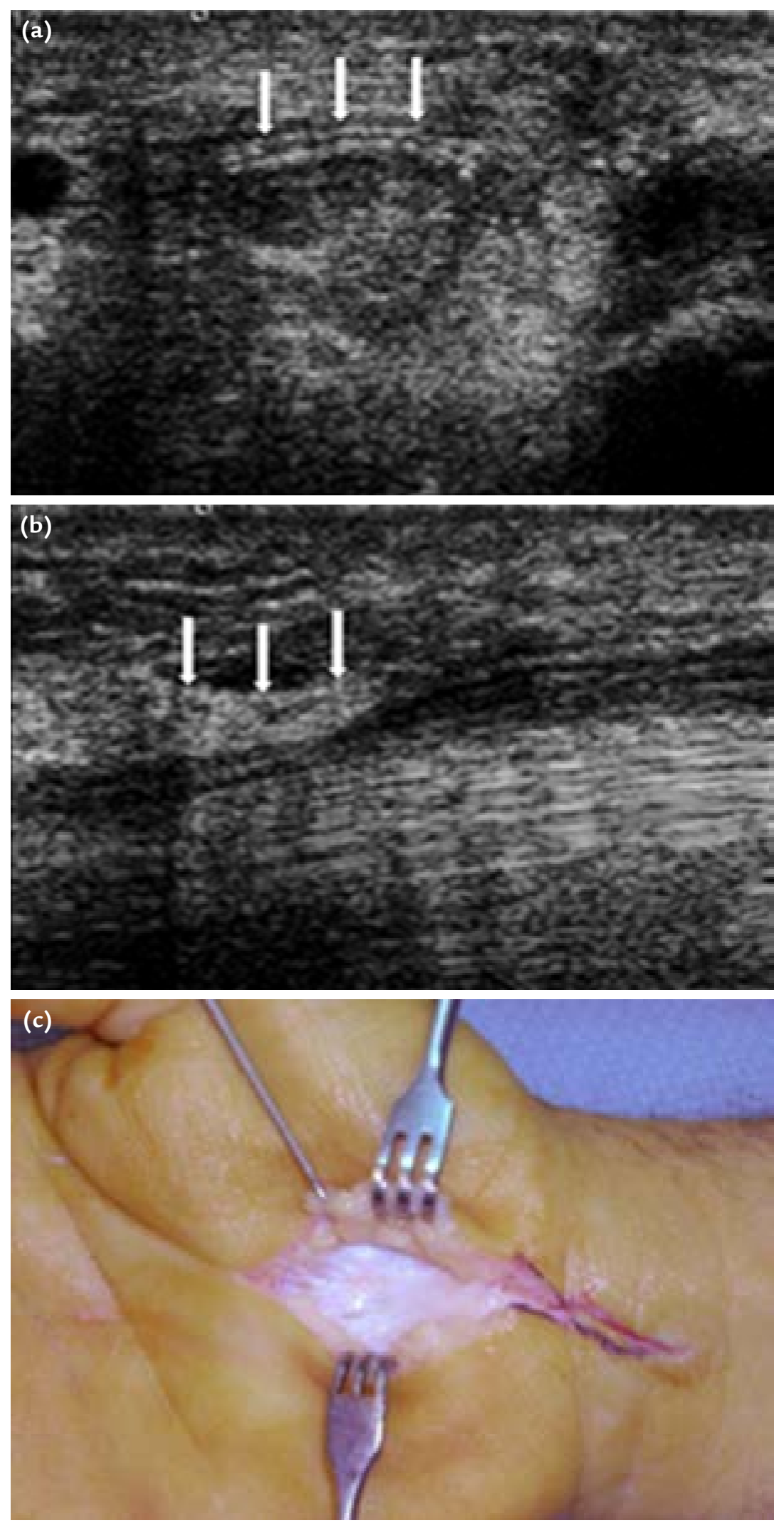

Şekil 2. a-c. Cerrahi gevşetme sonrası yakınmaları geçmemiş bir hastada, açılmamış transvers karpal ligamanın transvers (a), longitudinal (b) US ve ameliyat sırasındaki (c) görüntüleri. 

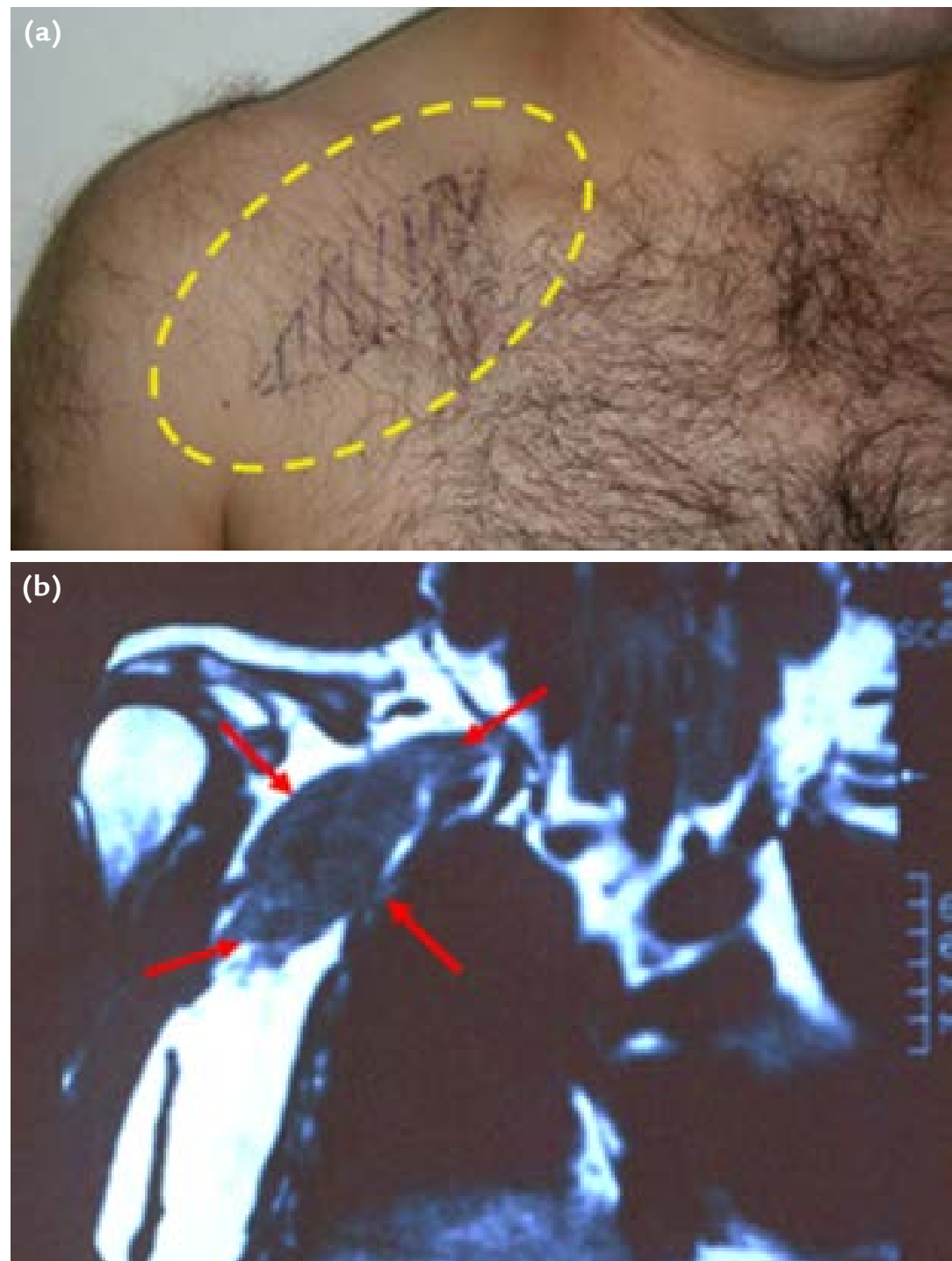

Şekil 3. a, b. KuTS tanısıyla ameliyat edilen n. ulnaris kökenli yuvarlak hücreli sarkom olgusu.

KuTS düşündüğümüz hastalarda, dirseğin radyolojik, US ve EDT'lerini rutin olarak yapıyoruz. Olası sıkışma noktalarında, ulnar sinir morfolojik yapısındaki değişiklikleri (ödem, perinöral fibrozis, nöroma formasyonu vb.), tünel içi patolojileri ve ankoneus epiktroklearis kasının varlığını saptamada US çok yararlı olmaktadır. Atipik olgularda, KuTS'nin, servikal radikülopati, ulnar tünel sendromu, torasik çıkış sendromu (TOS), double crush sendromu ve Pancoast tm. ile ayırıcı tanısı yapılmalıdır.

\section{Konservatif Tedavi}

İntrensek kaslarda belirgin güçsüzlük-zayıflık gibi motor bulguları olmayan hastalarda (McGowan
Evre I), mutlaka, konservatif tedavi uyguluyoruz. Sık tekrarlayıcı dirsek fleksiyon-ekstansiyonu gerektiren işlerde çalışanlarda, ekstremitenin istirahati, ulnar sinir trasesinde bası oluşturan aktivitelerin modifikasyonu, dirsek ekstansiyon ateli ve anti-inflamatuvar ilaç tedavisi ile hasta izlenir (Şekil 4). Altıncı hafta kontrolünde, KuTS bulgularında azalma varsa tedaviye devam edilir. En az üç ay süreyle uygulanan konservatif tedaviye cevap alınamayan hastalarda, cerrahi tedavi planlanır.

\section{Cerrahi Tedavi}

Geçmişte bazı dönemlerde, in situ gevşetme ve mediyal epikondilektomi gibi yöntemleri kullanmış 


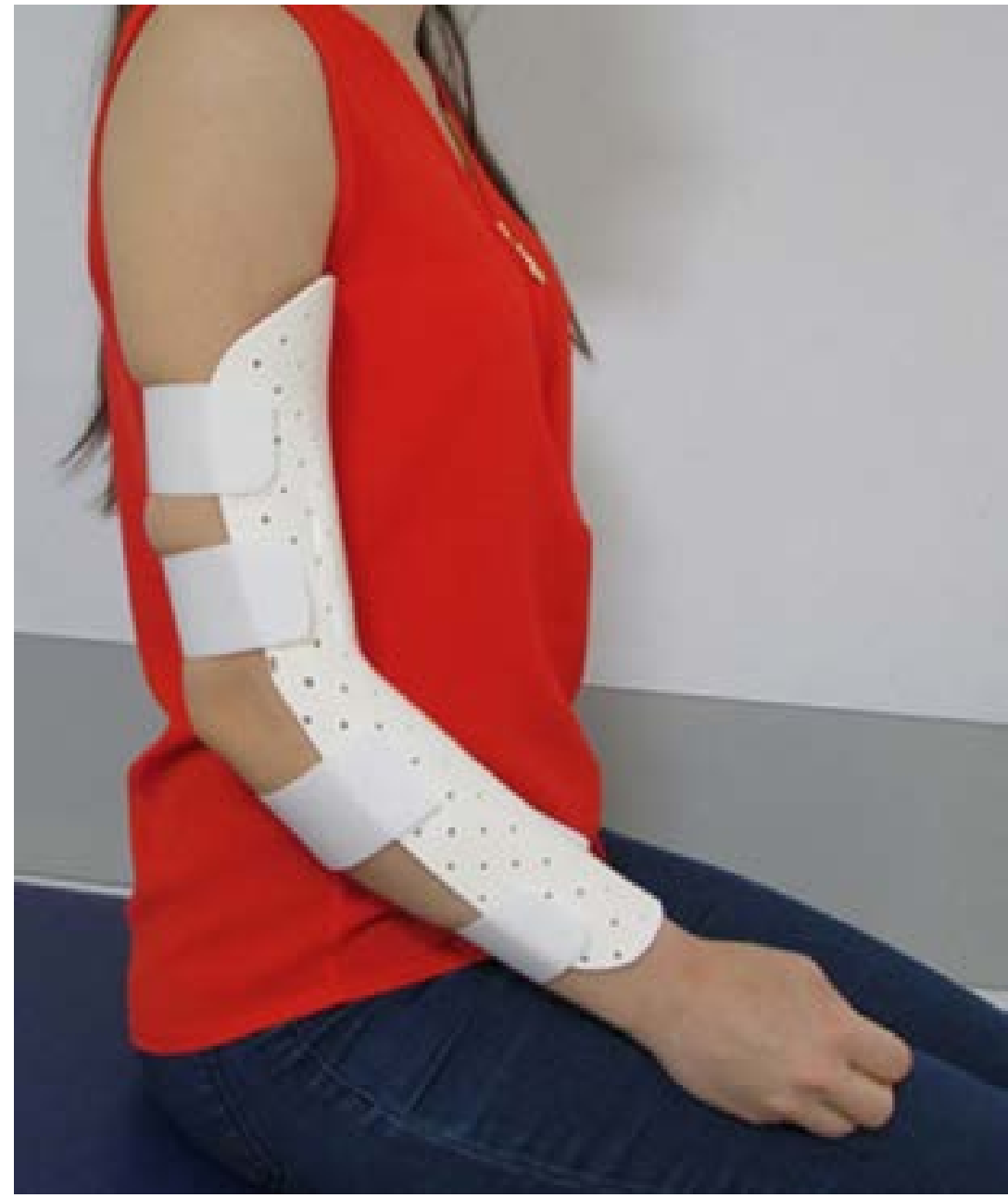

Şekil 4. KuTS konservatif tedavisinde kullandığımız dirsek ekstansiyon ateli.

olmamamıza rağmen, standart uygulamamız anterior cilt altı transpozisyon yöntemidir. İyi sonuç için, cilt kesisini çaprazlayan cilt altı duyu sinirlerinin (mediyal antebrakiyal sinirin posterior dalları) korunması, tüm potansiyel tuzaklanma bölgelerinde ulnar sinirin gevşetilmesi, mediyal intermusküler septum rezeksiyonu ve ulnar sinirin eşlik eden vasküler yapılarla birlikte serbestleştirilmesine özen gösterilmelidir (Şekil 5). Ayrıca, öne alınan ulnar sinirin dirsek fleksiyonu sırasında distalde katlanmaması için, fleksör kas fasyasının yeterince gevşetilmesi ve ulnar sinirin yeni pozisyonu korumak için fasyodermal askı oluşturulması, önemsediğimiz ayrıntılardır. ${ }^{[7]}$ Ameliyat sonrası, 5-7 gün süreyle dirsek fleksiyonda uzun kol ateli uygulamasını takiben, ekstremitenin günlük kullanımına izin veriyoruz.

Bu yöntem ile tedavi ettiğimiz hastaların bazılarında, dirsek posteriorunda geçici hipoestezi dışında bir sorunla karşılaşmadık.

\section{Nüks KuTS'ye yaklaşım}

Nüks KuTS ile başvuran hastalarda, iki farklı durum tanımlanabilir. Cerrahi gevşetme sonrası semptom ve bulgular hiç geçmediyse veya daha kötüleştiyse, öncelikle yanlış tanı olasılığı düşünülmelidir; servikal radikülopati, ulnar tünel sendromu, torasik çıkış sendromu (TOS), double crush sendromu, Parsonage-Turner sendromu, Pancoast tm. ekarte edilmelidir. KuTS tanısı doğruysa, yetersiz gevşetmeye odaklanmalıdır.

Ameliyattan sonra semptomlar ve bulgular düzelip, bir süre sonra (genellikle altı ay içinde) tekrar başlayabilir. Bu tür nüksün başlıca nedenleri arasında, mediyal antebrakiyal duyu dallarının yaralanmasına bağlı nöromalar, perinöral fibrozis/skatris, ulnar sinirin subluksasyonu, transpozisyon sırasında yeni tuzaklanma bölgelerinin oluşması sayılabilir. Nüks nedeni kesin olarak saptandıktan sonra tedavi planlanmalıdır. 

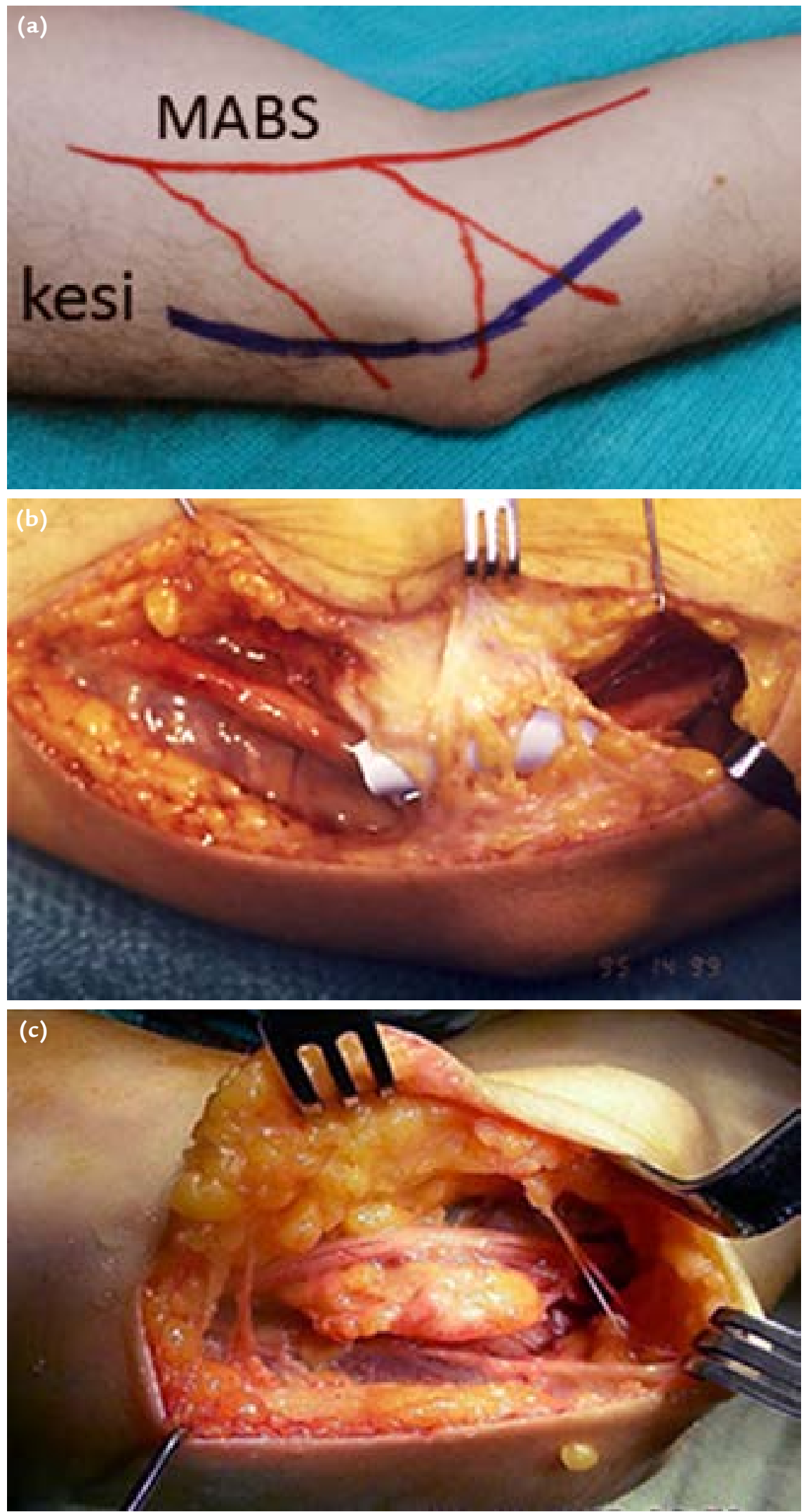

Şekil 5. a-c. Klasik KuTS kesisi ile mediyal antebrakiyal sinirin (MABS) posterior dalları ilişkisi (a). Mediyal antebrakiyal sinirin (MABS) dallarının korunduğu olgu örnekleri (b, c). 
Genel olarak, tuzak nöropatilerine yaklaşımımızı özetleyecek olursak:

- Tanıda hiçbir yöntem, öykü ve fizik muayene kadar değerli değildir.

- Lokal bulgular çok önemlidir.

- Tuzak nöropatilerine çok benzer bulgular veren sistemik hastalık ve tümörler unutulmamalıdır.

- Elektromiyografi, US ve MR, ayırıcı tanıya önemli katkı sağlamaktadır.

\section{KAYNAKLAR}

1. Lundborg G. Chronic nerve compression. In: Lundborg G, editor. Nerve injury and repair. Philadelphia: Churchill Livingstone, 1988.

2. Szabo RM, Slater RR Jr, Farver TB, Stanton DB, Sharman WK. The value of diagnostic testing in carpal tunnel syndrome. J Hand Surg Am 1999;24(4):704-14.
3. Shores JT, Lee WP. An evidence-based approach to carpal tunnel syndrome. Plast Reconstr Surg 2010;126(6):2196204. CrossRef

4. Karabay N, Toros T, Çetinkol E, Ada S. Correlations between ultrasonography findings and surgical findings in patients with refractory symptoms after primary surgical release for carpal tunnel syndrome. Acta Orthop Traumatol Turc 2015;49(2):126-32. CrossRef

5. Hall B, Lee $H C$, Fitzgerald $H$, Byrne $B$, Barton $A$, Lee $\mathrm{AH}$. Investigating the effectiveness of full-time wrist splinting and education in the treatment of carpal tunnel syndrome: a randomized controlled trial. Am J Occup Ther 2013;67(4):448-59. CrossRef

6. Soltani AM, Allan BJ, Best MJ, Mir HS, Panthaki ZJ. A systematic review of the literature on the outcomes of treatment for recurrent and persistent carpal tunnel syndrome. Plast Reconstr Surg 2013;132(1):114-21. CrossRef

7. Macadam SA, Gandhi R, Bezuhly M, Lefaivre KA. Simple decompression versus anterior subcutaneous and submuscular transposition of the ulnar nerve for cubital tunnel syndrome: a meta-analysis. J Hand Surg Am 2008;33(8):1314.e1-12. CrossRef 